\title{
Nonlinearity of Uniaxial Compressive Response in Atmospheric Plasma Sprayed Free-Standing CoNiCrAlY Coatings"
}

\author{
Hiroyuki WAKI $^{* *}$, Izuru NISHIKAWA ${ }^{* * *}$ and Akira KOBAYASHI ${ }^{* * * *}$ \\ ${ }^{* *}$ Department of Mechanical Engineering, Osaka Electro-Communication University, \\ 18-8 Hatsu-cho, Neyagawa, Osaka 572-8530, Japan \\ E-mail : waki@isc.osakac.ac.jp \\ *** Department of Mechanical Engineering, Osaka Institute of Technology, \\ 5-16-1 Ohmiya, Asahi-ku, Osaka 535-8585, Japan \\ ****Joining and Welding Research Institute, Osaka University, \\ 11-1 Mihogaoka, Ibaraki, Osaka 567-0047, Japan
}

\begin{abstract}
CoNiCrAlY protective coatings are used for insulation from corrosion and oxidation of super alloy substrates in gas turbine blades. The life of a gas turbine blade is significantly affected by the mechanical properties of the protective coating. However, the properties of the coatings themselves have not been clarified, because there are few proper measurement methods for thin coatings. In this study, uniaxial stress-strain responses of atmospheric plasma sprayed (APS) free-standing CoNiCrAlY coatings were examined. The coating specimen was tube with the thickness of $0.3 \mathrm{~mm}$. Coating specimens independent of substrates were fabricated by chemically dissolving out the substrates only at the region of gauge area. The stress-strain response was measured using the laser speckle strain measurement method. The coating showed the significant nonlinear stress-strain response. The stiffness increased with an increase of applied compressive stress, and the coating left permanent strain when the compressive stress was released. The nonlinearity of stress-strain response became significant if the surface roughness increased. The nonlinearity was decided by the surface roughness which represented the amount of defects in the coating. On the contrary, the nonlinearity was not proportional to the fraction of oxidized area. As compared with low pressure plasma sprayed (LPPS) CoNiCrAlY, the Young's modulus of APS CoNiCrAlY was low.
\end{abstract}

Key words: Mechanical Properties, CoNiCrAlY, Protective Coating, Plasma Spray, Thermal Barrier Coating, Laser Speckle

\section{Introduction}

CoNiCrAlY protective coatings are used for insulation from corrosion and oxidation of super alloy substrates in gas turbine blades. The life of a gas turbine blade is significantly affected by the mechanical properties of the protective coating ${ }^{(1)(2)}$. However, the properties of the coatings themselves are not clarified, because there are few proper measurement methods for thin coatings. Socie et. al. ${ }^{(3)(4)}$ developed the new method to measure the uniaxial stress-strain response of thick circular tube free-standing $\mathrm{ZrO}_{2}-8 \% \mathrm{Y}_{2} \mathrm{O}_{3}$ (8YSZ) coating. Authors ${ }^{(5)(6)}$ modified the method to apply to thin coating, and stress-strain responses of 8YSZ coating and CoNiCrAlY(LPPS) coating were measured. Authors have 
also developed the new easy method to measure the mechanical properties using a lateral compression of circular tube ${ }^{(7)}$. In this study, stress-strain responses of CoNiCrAlY(APS) coatings were measured at room temperature and $873 \mathrm{~K}$ by uniaxial compression of the circular tube specimen. The effect of spraying powder on the stress-strain response was discussed with the microstructures.

\section{Experimental Method}

\subsection{Manufacturing Procedure of the Specimens}

Specimens of CoNiCrAlY metallic coatings, which were independent of substrates, were manufactured in order to measure stress-strain responses of the coatings. The specimen was the uniaxial cylindrical specimen with the stainless steel screw ends. The manufacturing procedure of the specimen is shown in Fig. 1. First, as shown in Fig. 1(a), a mild steel tube with a thickness of $1 \mathrm{~mm}$ was fitted into the stainless steel cone jigs which had screws. Next, as shown in Fig. 1(b), thermal spraying was carried out on the center (testing area) of the fabricated substrate after blast processing by alumina grid (WA\#24). Finally, the coating specimen which had screw ends as shown in Fig. 1(c) was obtained by dissolving out only the mild steel tube by means of nitric acid. The steel substrate was dissolved out only from the inner surface. Thicknesses of all the coatings were approximately $300 \mu \mathrm{m}$. As the section area was large, the loading test was not hard. Furthermore, buckling didn't occur in such a thin coating, because the second moment of the section area was large.

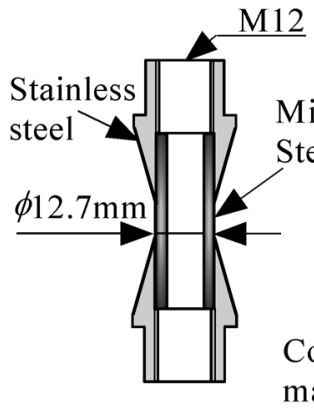

(a)

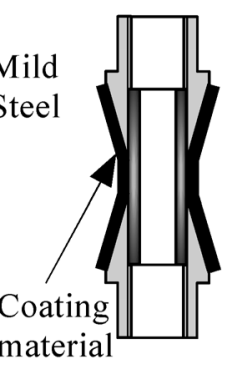

(b)

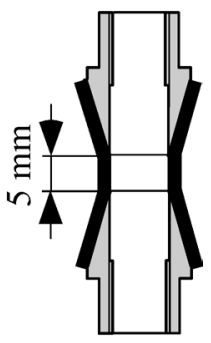

(c)

Fig. 1 Manufacturing procedure of the coating specimen: (a) mild steel tube with stainless steel ends before spraying, (b) with sprayed coating, (c) after dissolving out the mild steel tube

Table 1 Plasma-spraying conditions

\begin{tabular}{c|c|c}
\hline \hline \multicolumn{2}{c|}{ Pressure $(\mathrm{MPa})$} & 0.1 \\
\hline \multicolumn{2}{c}{ Arc current $(\mathrm{A})$} & 500 \\
\hline \multicolumn{2}{c}{ Arc voltage $(\mathrm{V})$} & 60 \\
\hline \multirow{3}{*}{ Arc gas } & $\operatorname{Ar}(\mathrm{MPa})$ & 0.69 \\
\cline { 2 - 3 } & $\mathrm{He}(\mathrm{MPa})$ & - \\
\cline { 2 - 3 } & $\mathrm{H}_{2}(\mathrm{MPa})$ & 0.41 \\
\hline \multicolumn{2}{c}{ Spraying distance $(\mathrm{mm})$} & 150 \\
\hline
\end{tabular}

Table 2 Specimens used in this study

\begin{tabular}{l|c|c}
\hline \hline Abbreviation of coating & $\begin{array}{l}\text { Spraying } \\
\text { condition }\end{array}$ & $\begin{array}{l}\text { Spraying } \\
\text { powder size }(\mu \mathrm{m})\end{array}$ \\
\hline CoNiCrAlY(APS-21) & & 21 \\
CoNiCrAlY(APS-37) & APS & 37 \\
CoNiCrAlY(APS-60) & & 60 \\
\hline
\end{tabular}




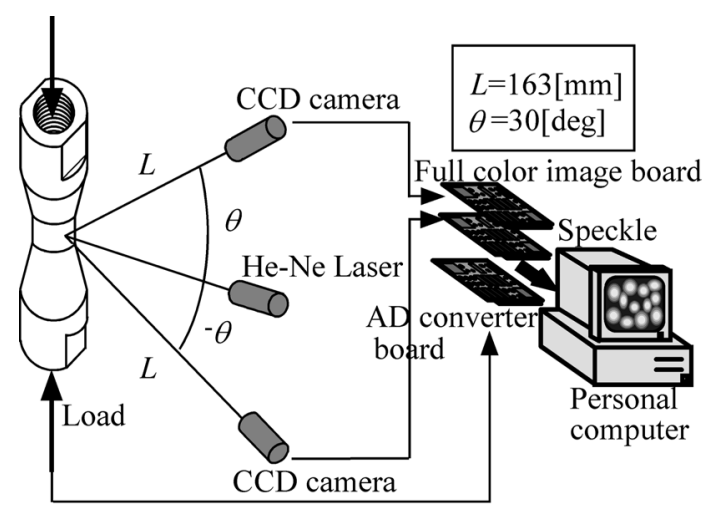

Fig. 2 Experimental setup for surface strain measurement using laser speckle strain measurement system

The coatings were deposited by atmospheric plasma spraying (APS). The spraying powder consisted of $38.5 \% \mathrm{Co}, 32 \% \mathrm{Ni}, 21 \% \mathrm{Cr}, 8 \% \mathrm{Al}$ and $0.5 \% \mathrm{Y}$. The spraying conditions and the three types of the specimens are shown in Table 1 and Table 2, respectively.

\subsection{Stress-Strain Measurement Method}

In order to investigate the uniaxial stress-strain responses of sprayed coatings, a quasi-static monotonic compression test was carried out. The tests were carried out at $873 \mathrm{~K}$ and room temperature. The electro-hydraulic servo fatigue testing machine $( \pm 2 \mathrm{kN})$ were used for loading the specimen. Loading speed was approximately $5 \mathrm{MPa} / \mathrm{sec}$ under the condition of load control. A laser speckle strain / displacement gauge (SSDG) developed by authors was used for measuring a strain of the specimen. The details of SSDG were described in previous papers ${ }^{(8)(9)}$. The gauge length was selected as $1 \mathrm{~mm}$. In case of high temperature test, specimens were heated by an electric furnace. The schematic illustration of the experimental setup is shown in Fig. 2. The resolution in the strain measurement depends on both the arrangements of CCD cameras and the number of pixels of an image processing board. The measurement system used in this study had a resolution of $0.06 \%$ strain.

\section{RESULTS AND DISCUSSIONS}

\subsection{Microstructures}

The plasma-spraying produced the coatings which had complicated microstructures. Longitudinal-sections of coatings were observed using a scanning electron microscope (SEM). The composition images of the coatings are shown in Figs. 3(a) (c). In addition, the coatings are laminated in the lateral direction of the Figs, and the loading directions of specimens are the vertical direction of the Figs. As shown in Figs. 3(a) (c), CoNiCrAlY coatings deposited by APS have the laminated structures with much oxide which look black in the Figs.

The fraction of oxidized area was measured by image processing. The composition images, Figs. 3(a) (c), were converted into black and white images, and the black ratio, fraction of oxidized area, was estimated. Figure 4 shows the fraction of oxidized area plotted against the spraying powder size. The fraction of oxidized area increases with a decrease of spraying powder size. It is also found from Figs. 3(a) (c) that there are much small size of oxidation in CoNiCrAlY(APS-21). Small spraying powder had larger oxidized surface than large spraying powder. It was the reason of high fraction of oxidized area in CoNiCrAlY(APS-21).

Surface roughness, $R_{\mathrm{a}}$, was also measured from longitudinal section images by image processing. $R_{\mathrm{a}}$ is also shown in Fig. 4. $R_{\mathrm{a}}$ increases with an increase of spraying powder size. It was reported that the porosity of CoNiCrAlY coating was directly correlated with 

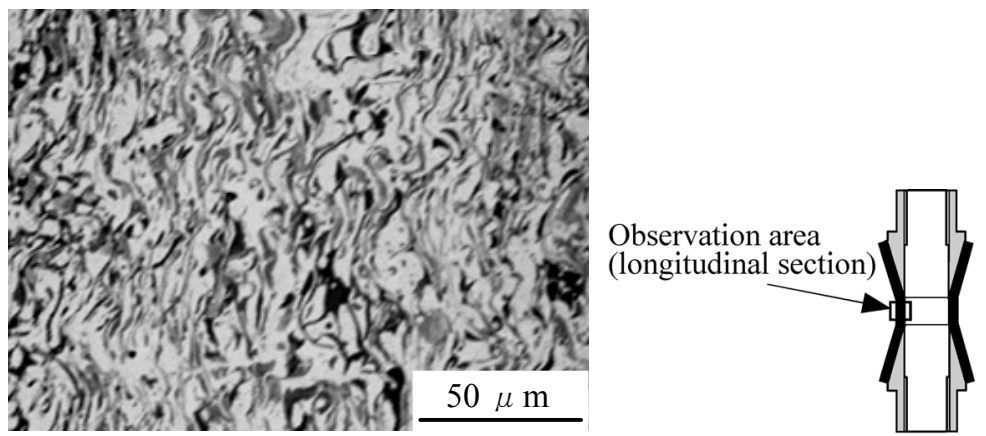

(a) $\mathrm{CoNiCrAlY}(\mathrm{APS}-21)$

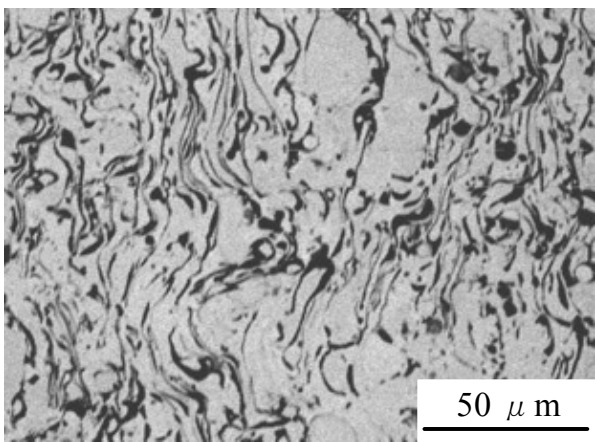

(b) CoNiCrAlY(APS-37)

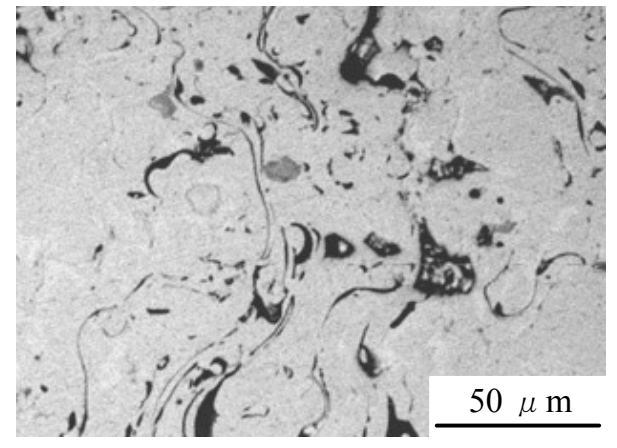

(c) $\mathrm{CoNiCrAlY}(\mathrm{APS}-60)$

Fig. 3 Microstructures of CoNiCrAlY(APS) coatings

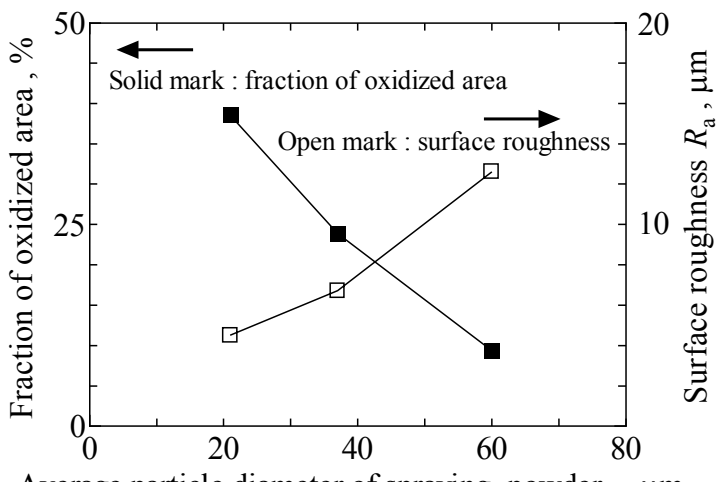

Average particle diameter of spraying-powder, $\mu \mathrm{m}$

Fig. 4 Fraction of oxidized area and surface roughness of each coating

surface roughness ${ }^{(10)}$. In this study, $R_{\mathrm{a}}$ was used as a representative parameter instead of the amount of pores or cracks between platelets.

\subsection{Stress-Strain Response}

The typical examples of the compressive deformation behaviors of CoNiCrAlY coatings at room temperature and $873 \mathrm{~K}$ are shown in Figs. 5(a)and(b), respectively. The loading method of a specimen was as follows: First, compressive load was applied along the line from point $\mathrm{O}$ to point $\mathrm{A}$. Next, the compressive load was removed along the line from point A to point B. After that, a compressive load was applied again along the line from point $\mathrm{B}$ to point $\mathrm{C}$. Next, the compressive load was removed along the line from point $\mathrm{C}$ to point D. Finally, a compressive load was applied again along the line from point $\mathrm{D}$ to point C. In short, the compressive load was stepwise increased by -50MPa. It is found from Figs. 5(a)and(b) that CoNiCrAlY(APS) coating shows nonlinear stress-strain response.

Next, stress-strain responses are quantitatively investigated. The stress-strain curve 

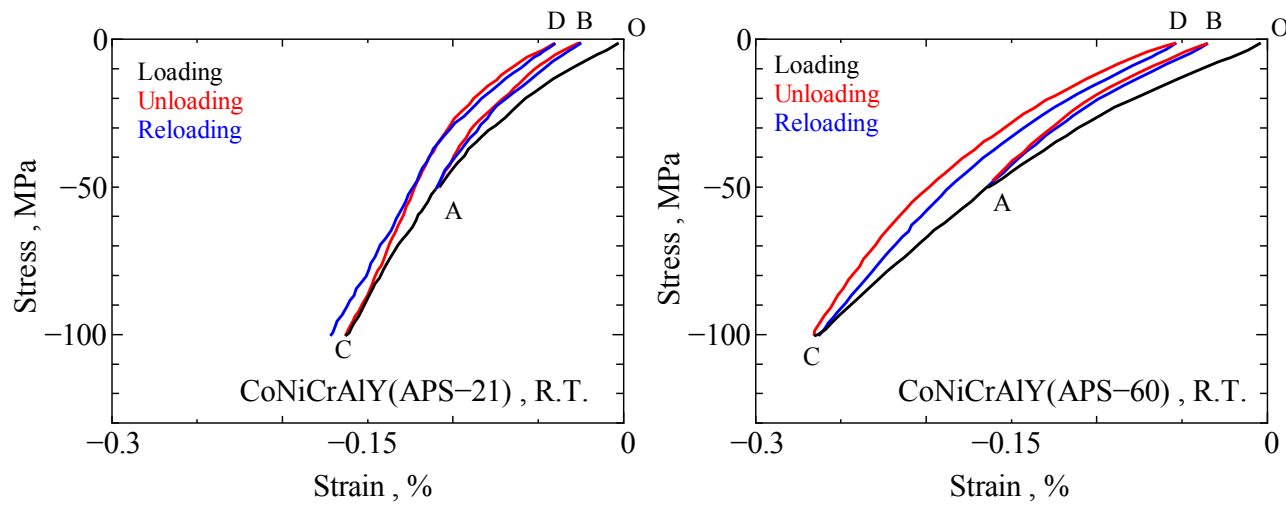

(a) R.T.

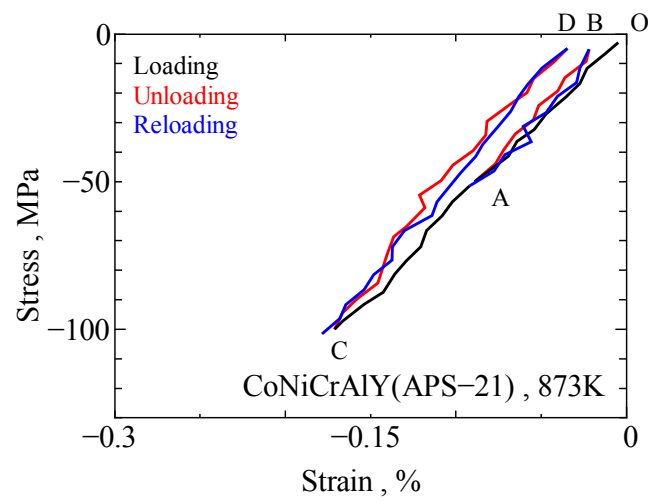

(b) $873 \mathrm{~K}$

Fig. 5 Compressive stress-strain response under stepwise loading

loaded with compressive load at the first time is named initial-load-line, and the curve at the part of removing compressive load toward a zero stress is named unload-line, and the curve loaded with compressive load once again is named reload-line. As shown in Figs. 5(a)and(b), the unload-line $A B$ which has the larger slope is different from the initial-load-line OA both at R.T. and 873K. It means that a permanent strain appears both at R.T. and $873 \mathrm{~K}$. There is also a tendency at R.T that the tangent of stress-strain is higher at high stress region than at low stress region. On the contrary, the tangent of stress-strain is nearly linear at $873 \mathrm{~K}$. The difference of the stress-strain form was because creep was high in high compressive stress region at high temperature. The reload-line $\mathrm{BC}$ passes near the unload-line $\mathrm{AB}$ both at R.T. and $873 \mathrm{~K}$. When stress exceeds the maximum compressive stress undergone, the strain increases and the stress-strain line follows the extension line of the initial-load-line OA. Then, when compressive load is given stepwise, the coatings show the similar deformation behavior. It was found that the coatings remembered a loading history, and that a permanent strain appeared by undergoing compressive load. It was the same deformation behavior as the nonlinear stress-strain response of the uniaxial compressive load in a thick thermal barrier $\mathrm{ZrO}_{2}-8 \% \mathrm{Y}_{2} \mathrm{O}_{3}$ coating which Socie et. al. ${ }^{(3)(4)}$ had reported.

Next, total strain range was investigated. Figure 6 shows the total strain range generated under $\Delta \sigma=100 \mathrm{MPa}$ plotted against a spraying powder size. It is found that the total strain range increases with an increase of the powder size. Figure 7 shows the total strain range plotted against the surface roughness $R_{\mathrm{a}} . R_{\mathrm{a}}$ is a representative parameter instead of the amount of pores or cracks between platelets. It is found that the total strain range increases with an increase of $R_{\mathrm{a}}$. Itoh et. al. had also reported that CoNiCrAlY coating with high density had high Young's modulus and high strength ${ }^{(11)}$. It is also found from Fig.7 that the total strain range of CoNiCrAlY(APS-21) at $873 \mathrm{~K}$ is not significantly different from that at 


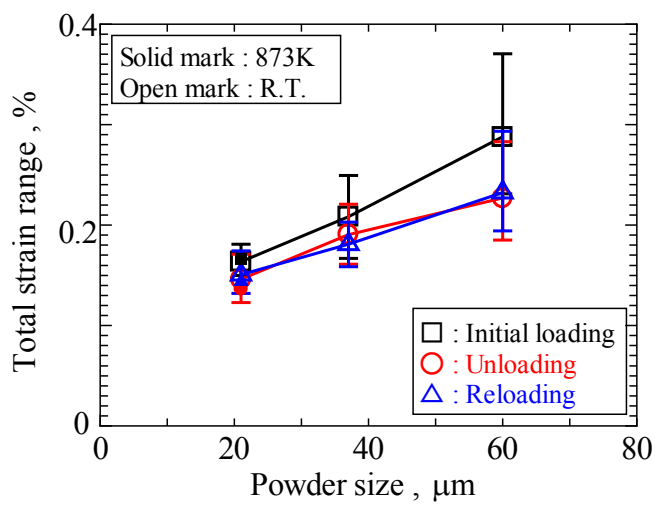

Fig. 6 Total strain range generated under $\Delta \sigma=100 \mathrm{MPa}$ plotted against the spraying powder size

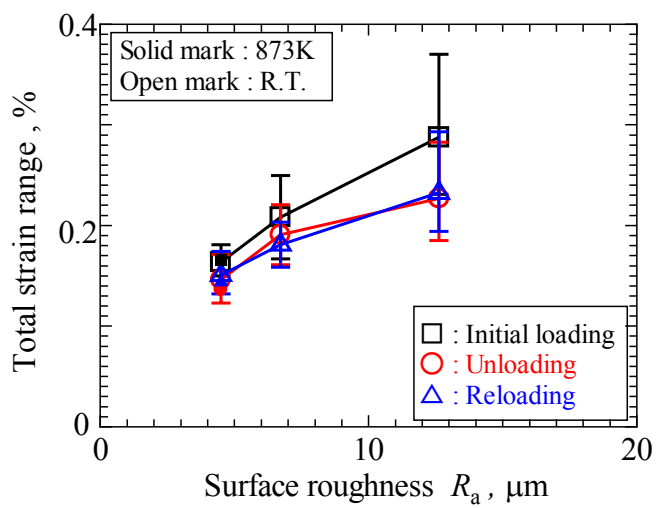

Fig. 7 Total strain range generated under $\Delta \sigma=100$ MPa plotted against the surface roughness

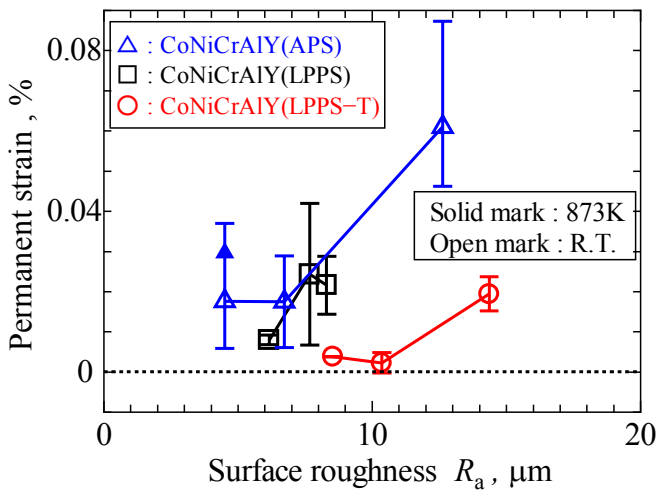

Fig. 8 Permanent strain range generated under $\Delta \sigma=100 \mathrm{MPa}$ plotted against the surface roughness

R.T.

Next, permanent strain was investigated. Figure 8 shows the permanent strain generated under $\Delta \sigma=100 \mathrm{MPa}$. The permanent strain of CoNiCrAlY(LPPS) which had reported in previous paper ${ }^{(6)}$ is also plotted in Fig. 8. CoNiCrAlY(LPPS-T) means the CoNiCrAlY(LPPS) specimen with thermal treatment which consisted of $1327 \mathrm{~K} 3$ hours in vacuum. It is found that the permanent strain increases with an increase of $R_{\mathrm{a}}$, and the permanent strain of CoNiCrAlY(APS) is the highest among the coatings. It is also found that the permanent strain at $873 \mathrm{~K}$ is higher than that at R.T.

Next, the strain range ratio of the average strain of unloading-strain range and reloading-strain range to initial-strain range, $R_{\mathrm{m}}$, is shown in Fig. 9. The strain ranges generated under $\Delta \sigma=100 \mathrm{MPa}$ shown in Fig. 6 were used for estimating the $R_{\mathrm{m}}$. If $R_{\mathrm{m}}$ is 


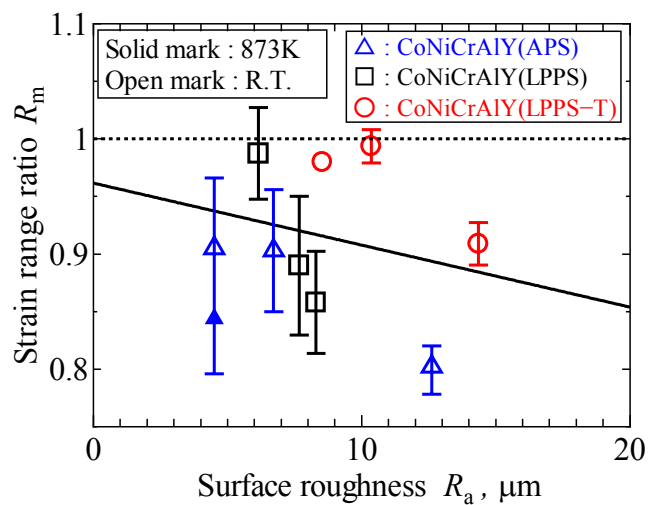

Fig. 9 The strain range ratio of the average strain of unloading-strain range and reloading-strain range to initial-strain range, $R_{\mathrm{m}}$

lower than 1.0, it means the coating shows hardening. The $R_{\mathrm{m}}$ of CoNiCrAlY(LPPS) coating ${ }^{(6)}$ is also plotted in Fig. 9. It is found that $R_{\mathrm{m}}$ decreases with an increase of $R_{\mathrm{a}}$ and the $R_{\mathrm{m}}$ of CoNiCrAlY(APS) is the lowest among the coatings. It is also found that the $R_{\mathrm{m}}$ at $873 \mathrm{~K}$ is lower than that at R.T. It is found from these results that the compliance of the stress-strain curve decreased by undergoing monotonic compressive load.

In short of this section, CoNiCrAlY(APS) showed significant nonlinear stress-strain response. The nonlinearity was decided by the surface roughness which represented the amount of defects in the coating and it was significant if the surface roughness increased. On the contrary, the nonlinearity was not proportional to the fraction of oxidized area. There were not significant differences between the stress-strain response of CoNiCrAlY(APS-21) at $873 \mathrm{~K}$ and that at R.T.

\subsection{Apparent Young's Modulus}

The tangent modulus of stress-strain curve obtained was investigated quantitatively. Tangent modulus of an initial-load line at each stress is shown in Fig. 10. The value of modulus increases with increasing compressive stress at R.T. as shown in Fig. 10. This means that the stress-strain curves are convex curves at R.T. On the contrary, the modulus is nearly constant at $873 \mathrm{~K}$. This means the stress-strain curve is nearly linear at $873 \mathrm{~K}$. Since the compaction of micro pores was the one of the deformation mechanism, the stress-strain responses at R.T. showed convex curves. At high temperature, the nonlinearity was canceled by creep, so that it showed nearly linear stress-strain response.

Next, tangent modulus of initial-line at near zero stress, apparent Young's modulus, was investigated. It is understood from Fig. 11 that apparent Young's moduli of coatings are low as compared with bulk alloy. It is also found that apparent Young's modulus of CoNiCrAlY

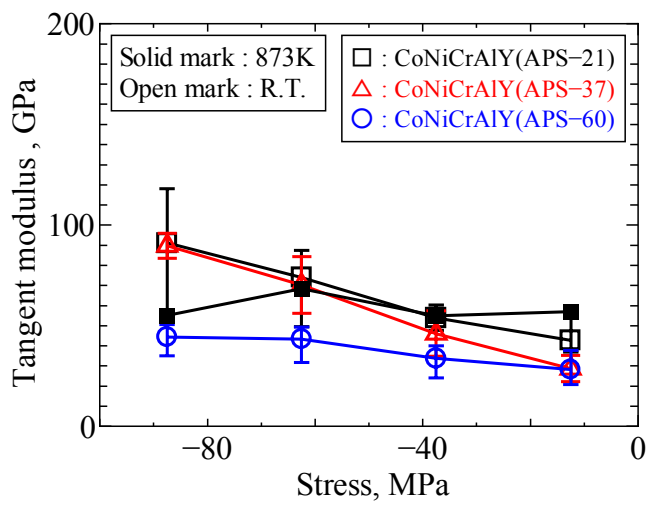

Fig. 10 Tangent modulus at each stress 


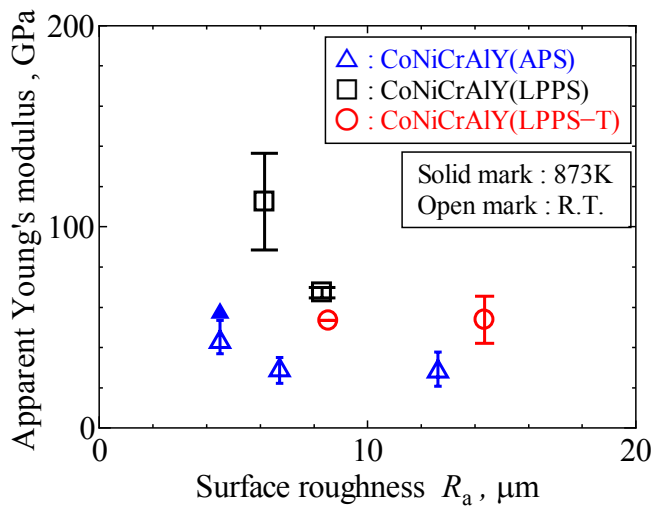

Fig. 11 Apparent Young's modulus

(APS) is the lowest, and those of CoNiCrAlY (LPPS) and CoNiCrAlY(LPPS-T) are almost the same. It is the same results by lateral compression of circular tube coating ${ }^{(7)}$. The apparent Young's modulus increases with a decrease of $R_{\mathrm{a}}$. It is also found that apparent Young's modulus at $873 \mathrm{~K}$ is a little higher than that at R.T. Authors confirmed that Young's modulus does not decrease until at $873 \mathrm{~K}$ and that at $873 \mathrm{~K}$ was a little higher than that R.T. by lateral compression of circular tube CoNiCrAlY(APS).

\section{Conclusion}

Free-standing CoNiCrAlY sprayed coating specimens whose thicknesses were approximately $300 \mu \mathrm{m}$ were developed. The uniaxial stress-strain response of CoNiCrAlY(APS) were measured using the laser speckle strain / displacement gauge at R.T. and $873 \mathrm{~K}$. The results obtained are summarized as follows:

(1) The coatings had much oxide if the coatings were sprayed using small diameter of spraying powder. On the contrary, the coatings had low surface roughness.

(2) CoNiCrAlY(APS) coating showed significant nonlinear stress-strain response. The stiffness increased with an increase of applied compressive stress, and the coating left permanent strain when the compressive stress was released.

(3) The total strain range and permanent strain increased with an increase of the surface roughness which represented the amount of defects in the coating.

(4) Nonlinearity of stress-strain response became significant if the surface roughness increased. The nonlinearity was decided by the surface roughness which represented the amount of defects in the coating. While, the nonlinearity was not proportional to the fraction of oxidized area.

(5) Apparent Young's modulus of CoNiCrAlY(APS) was lower than that of CoNiCrAlY (LPPS). The Young's modulus increased with a decrease of surface roughness.

\section{Acknowledgement}

Authors acknowledge the financial support by the Ministry of Education, Science, Sports and Culture, Grant-in-Aid for Young Scientists (B), 18760089.

\section{References}

(1) Itoh, Y., The Present Situation and View of Thermal Barrier Coating Based on Mechanical Properties (in Japanese), Science of Machine, Vol.47, No.11(1995), pp.1150-1154.

(2) Okazaki, M., High-Temperature Strength of Ni-Base Super Alloy Coatings, Science and 
Technology of Advanced Materials, Vol. 2, Issue 2(2001), pp.357-366.

(3) Rejda, E.F., Socie, D.F. and Beardsley, B., Fatigue Behavior of a Plasma-Sprayed $8 \% \mathrm{Y}_{2} \mathrm{O}_{3}-\mathrm{ZrO}_{2}$ Thermal Barrier Coating, Fatigue \& Fracture of Engineering Materials \& Structures, Vol.20(1997), pp. 1043-1050.

(4) Rejda, E.F, Socie, D.F and Itoh, T., Deformation Behavior of Plasma-Sprayed Thick Thermal Barrier Coatings, Surface and Coatings Technology, Vol.113(1999), pp. 218-226.

(5) Waki, H., Ogura, K., Nishikawa, I. and Ohmori, A., Monotonic and Cyclic Deformation Behavior of Plasma-Sprayed Coatings under Uni-Axial Compressive Loading, Materials Science and Engineering A, Vol. 374, Issue 1-2(2004), pp. 129-136.

(6) Waki, H., Takeuchi, K., Nishikawa, I. and Ohmori, A., Mechanical Properties of Low Pressure Plasma Sprayed CoNiCrAlY Coatings by Uniaxial Compression, Applied Plasma Science, Vol.12(2004), pp. 80-86.

(7) Waki, H. and Kobayashi, A., Development of Lateral Compression Method of Circular Tube Thin Coating for Mechanical Properties of Plasma Sprayed CoNiCrAlY, Material Transactions, Vol.47, No.7(2006), pp. 1626-1630.

(8) Nishikawa, I., Ogura, K., Yamagami, M. and Kuwayama, K., New Development of Laser Speckle Strain/Displacement Gage for the Measurement of Fracture Mechanics Parameters, Journal of the Society of Materials Science, Japan, Vol.43, No.493(1994), pp. 1290-1296.

(9) Waki, H., Ogura, K. and Nishikawa, I., Notch Root Biaxial Cyclic Strain Behavior of Type 304 Stainless Steel at Elevated Temperature Using Laser Speckle Strain / Displacement Gauge, JSME International Journal, Series A, Vol. 44, No. 3(2001), pp. 374-382.

(10) Schmitt-Thomas, K.G., Haindl, H. and Fu, D., Modifications of Thermal Barrier Coatings (TBCs), Surface and Coatings Technology, Vol.94-95(1997), pp. 149-154.

(11) Itoh, Y., Saitoh, M. and Tamura, M., Characteristics of MCrAlY Coatings Sprayed by High Velocity Oxigen-Fuel Spraying System, Transactions of the ASME, Journal of Engineering for Gas Turbines and Power, Vol.122(2000), pp. 43-49. 